\title{
Sustainable Resource Use and Economic Dynamics
}

\section{Journal Article}

\section{Author(s):}

Bretschger, Lucas; Smulders, Sjak

Publication date:

2007

Permanent link:

https://doi.org/10.3929/ethz-b-000008980

\section{Rights / license:}

In Copyright - Non-Commercial Use Permitted

\section{Originally published in:}

Environmental and Resource Economics 36(1), https://doi.org/10.1007/s10640-006-9043-x 


\title{
Sustainable Resource Use and Economic Dynamics
}

\author{
LUCAS BRETSCHGER ${ }^{1, *}$ and SJAK SMULDERS ${ }^{2}$ \\ ${ }^{1}$ CER-ETH Center of Economic Research at ETH Zurich, ZUE F7, Zurich, CH-8092, \\ Switzerland; ${ }^{2}$ Department of Economics, Tilburg University, P.O. Box 90153 Tilburg, 5000 LE, \\ The Netherlands; *Author for correspondence (e-mail: lbretschger@ethz.ch)
}

Accepted 1 August 2006

\begin{abstract}
We argue that the sustainable use of natural resources has to be placed in a dynamic perspective, both in theoretical modelling and in applied research. This can be achieved by applying endogenous growth theory and other recent advances in dynamic theory. In this paper we discuss five contributions that combine the topics of natural resource use and economic dynamics. In particular, we show the common features of these contributions, thereby providing an overview of a very active and promising research area.
\end{abstract}

Key words: sustainability, natural resource use, economic dynamics

JEL classification: Q01, Q55, O13, O41

\section{Introduction}

There are many compelling reasons why environmental and resource problems should be placed in a dynamic perspective. Traditionally, resource economics needs to study the dynamics of depletion of natural resources and environmental services. Current use of non-renewables, such as oil reserves, determines future resource availability. Renewable natural resources regenerate in a dynamic ecological process, which is disturbed by commercial harvesting activities. Similarly, environmental economics has to deal with pollution dynamics when pollution entails long-lasting cumulative effects in soil and marine resources or in the atmosphere. Looking at the impact of resource scarcity and pollution for the economy as a whole we additionally find that macro-economic dynamics become highly relevant. To offset the increasing scarcity of natural resources and to promote sustainable development, capital accumulation and technological change are essential. In particular, the development and adoption of new technologies allow improving resource and abatement efficiency. Finally, social dynamics are important: the behaviour of polluters or natural resource users, as well policy makers, changes over time because of learning behaviour, or because of 
changing perceptions, the building up of new information, and the reaction thereupon.

The experience of the world economy with oil prices over the past few decades illustrates some of the interactions between resource dynamics and macro-economic dynamics. The present situation shows similarities with the 1970s and 1980s, when oil prices rose sharply and pollution issues entered the political agenda. In the last 4 years, the increase in oil prices was similar in scale to the price jumps of 1973-1974, 1978-1980 and 1989-1990, all of which were followed by worldwide recession and rising inflation. However, historical parallels have to be handled with great care. The big recession of the mid-1970s was not only due to oil shortages but was additionally caused by other facts like the breakdown of the Bretton-Woods currency system and a broad uncertainty about the growth perspectives in general. Also, in the nearer past, price increases of raw materials have been more gradual, giving households and firms more time to adjust. The most important difference to thirty years ago, however, is that developed countries use half as much oil per real unit of GDP as in the mid-1970s, thanks to improved energy efficiency, a switch to alternative energy sources, and the shift from manufacturing to services.

The concern for sustainability provides another illustration of the interaction between resource dynamics on the one hand and macro-economic and social dynamics on the other. After a long process of growing awareness and changing perceptions of links between resource use, environmental problems, poverty and intergenerational fairness, the notion of 'sustainable development' is nowadays widely accepted as a main principle for environmental and development policies. However, the concept of sustainable development as used in the policy debate and among noneconomists has been far away from the traditional welfare analysis in economics. Economists have succeeded to bridge a large part of the gap by taking explicitly into account natural resource constraints on output, studying resource markets, acknowledging externalities in resource use, and considering alternative ethical foundations for welfare functions and discounting principles. Accordingly, a large part of the formal literature on sustainability studies how utility levels can be sustained in a model world with (non-)renewable resources. Substitution has become the core of economists' view on sustainability. Over time, decreasing per capita amounts of natural inputs have to be sufficiently compensated for by the accumulation of man-made inputs. The greater the saving effort of the present generation is, the more feasible becomes the substitution of natural resources in production and consumption. The key research question for economists is to determine the returns and incentives of these sustainabilityenhancing investment activities. 
The dynamics of technological change cannot be ignored in this context: both as a threat to sustainability (in the guise of resource-using or energyusing technological change) or as the solution (more efficient resource use, clean technologies and backstops, i.e. resource-saving technological change). Understanding the sustainability of long-term development therefore requires insight into the pace, direction, and determinants of technical change. The new growth theory that started in the 1990s provides a modelling framework in which technological change is an endogenous variable: knowledge - embodied in new capital goods, production processes and products - is an ultimate substitute for resource inputs, without making the latter unnecessary. Developing useful new knowledge is costly and time-consuming, which turns innovation into an economic investment problem. Theories of endogenous innovation examine the incentives for innovation in a particular direction (resource-using versus resource-saving), as well as the opportunity cost of technological change resulting from crowding out of conventional investment by environmentally-oriented investment. Technological progress is often modelled as incremental, which leads to a steady, but possibly moderate improvement of resource efficiency. In addition, we need to look for technology options that bring about a quantum jump in the efficiency of using natural resources. Only with radical innovations will the economy be in a position to tame the increasing resource demand in the future, given the rapid economic development today, for example in China, India, and other emerging economies.

The complexity and breadth of sustainable development requires an even broader view, as reflected in the Millennium Development Goals, where the reduction of poverty, hunger, disease, illiteracy, and discrimination against women are the most important issues. In the future, economic analysis will be increasingly devoted to local community actions, the dynamics of social norms, and their impact on resource use in smaller groups.

The five papers in this special issue study different aspects of resource use, economic dynamics, and sustainability. The papers by Egli and Steger (2006) and Soretz (2006) study the incentives to invest in clean technologies, in particular in the presence of increasing returns to abatement activities and uncertainty, respectively. The paper by Cunha-e-Sá and Reis (2006) analyses a discrete jump in technology towards cleaner production. The empirics of gradual improvement and international convergence in aggregate energy efficiency is studied in the paper by Mulder and De Groot (2006). Finally, the paper by Noailly, Van den Bergh, and Withagen (2006) focuses on local communities and how social norms with respect to resource use evolve there. In the remainder of this article we discuss the main common elements and a unifying modelling framework for the five papers. 


\section{Modelling Growth and Pollution}

Growth and pollution have been studied extensively over the last decade, both empirically and theoretically. From an empirical perspective, the Environmental Kuznets Curve (EKC) hypothesis has been most visible, although most of the earlier work under this heading looks into the relationship between levels of income and pollution. Only recently has growth been explicitly studied (Bradford et al. 2005, Brock and Taylor 2004). The theoretical analysis builds on the "endogenous growth" literature developed in macroeconomics (starting with Romer 1986, see Aghion and Howitt 1998 for a broad exposition). The most elementary endogenous growth model, the "AK model", extended for basic environmental and resource aspects, provides important insights into the links between investment in production capacity and the resulting economic growth on the one hand, and the polluting consequences of production and environmental policy on the other.

There is still a big gap between the empirical and theoretical literature. The Environmental Kuznets Curve literature typically aims at characterizing the relationship between levels of income and pollution without linking empirical model specification to theory or testing for underlying mechanisms. The theoretical literature normally restricts the analysis to constant growth (or balanced growth) paths and ignores the richer dynamics emerging from the empirical EKC studies in which the pollution-income link changes over time or with income levels.

The papers by Cunha-e-Sá and Reis (2006), Egli and Steger (2006), and Soretz (2006) all further develop the AK model to investigate the relationship between economic growth and environmental policy. In particular, they introduce new dynamic elements that allow for a more detailed study of clean technology adoption, uncertainty, and the link to the EKC.

To give a clear view on how we can start to study environmental economic dynamics from the canonical AK-model, we first briefly review the AKapproach and then show how clean technology can be modelled, how the pollution-income link depends on abatement technology, and how uncertainty can matter in this context.

\subsection{THE ENVIRONMENTAL AK-FRAMEWORK}

The distinguishing feature of the AK model is that aggregate production in the economy, $Y$, is linearly related to a broad measure of reproducible capital, $K$, in the following way:

$$
Y=A K \text {. }
$$

Accordingly, the marginal product of capital is given by $A$; it determines the rate of return and incentives to invest. The aggregation of all relevant 
man-made capital goods into one stock variable that is linearly proportional to output simplifies the analysis considerably.

To incorporate environmental aspects into the AK-model, pollution can be modelled as a by-product of either inputs $(K)$ or consumption $(C)$; abatement expenditures $(E)$ are assumed to reduce pollution for given polluting input levels. Hence, the general formulation for the pollution generating process can be written as:

$$
P=p(K, C, E)
$$

where $p_{C} \geq 0, p_{K} \geq 0, p_{E} \leq 0$ (with the subscripts denoting first-order partial derivatives).

Pollution is assumed to affect (as an externality) both production, through an effect on productivity level $A$, and instantaneous utility $U$, which otherwise depends on consumption $C$. Thus we can write:

$$
\begin{aligned}
& A=a(P), \\
& U=u(C, P),
\end{aligned}
$$

where $a_{P} \leq 0, u_{C} \geq 0, u_{P} \leq 0$. Growth of output and levels of pollution are determined by the allocation of total production over consumption, capital investment, and pollution abatement. Investment in the economy $(d K / d t)$ and investment in the environment $(E)$ come at the cost of consumption $(C)$, according to the following goods market equilibrium condition:

$$
Y=C+E+d K / d t
$$

Now consider a balanced growth path along which all terms in (5) grow at the same rate so that the ratios $C / Y, E / Y$, and $(d K / d t) / Y$ are constant. If the pollution generating process in (2) has properties such that we can write it in the following specification:

$$
P=p(K / E, C / E, 1),
$$

pollution is constant along the balanced growth path, too. ${ }^{1}$ Thus, with the linear production function (1) and "ratio-dependent" pollution function (6), "sustainable growth" is feasible: output grows at a constant rate and pollution does not increase. There are no limits to growth in this case. If preferences are of the Cobb-Douglas type, a balanced growth path is not only feasible but also optimal with discounted utility maximization, see Smulders and Gradus (1996). A specification for preferences giving this result is $U=(1-\sigma)^{-1}\left[C \cdot(\bar{P}-P)^{\phi}\right]^{1-\sigma}$, where $\bar{P}$ is the critical value of pollution beyond which welfare cannot be sustained. With additive preferences, however, e.g. $U=(1-\sigma)^{-1} C^{1-\sigma}+(\bar{P}-P)^{\phi}$, it is optimal to 
spend a larger and larger part of output on abatement and to invest less and less in capital accumulation so that the growth process comes to an end (Stokey 1998).

Analytically, the model defined by (1)-(6) is an extremely convenient specification. Only one stock variable matters, viz. $K$, and no transitional dynamics arise. However, the specification in (6) might be seen as an overly optimistic view: doubling capital, consumption and abatement does not double pollution but in fact leaves pollution unaffected. This implicitly assumes strong learning effects or technological change that offset the "scale effect", defined as the tendency of pollution to expand with the scale of economic activity, keeping fixed the production technology and the composition of output (cf. Brock and Taylor 2005). A standard replication argument would produce a completely different result: doubling all inputs would double all outputs, like building next to a factory another identical factory would double pollution. The absence of constant returns to scale calls for an explanation in terms of increasing returns or technological change. First, when expanding the scale of the economy the productivity of abatement might increase (or the polluting consequences of capital might diminish) due to increasing returns: new firms that enter the economy bring new knowledge, broaden the scope for learning and experimenting, and might thus increase the productivity of abatement. Alternatively, over time technological change may improve the productivity of abatement or may cause pollution per unit of output to fall.

The environmental growth models by Cunha-e-Sá and Reis (2006) and Egli and Steger (2006) make the learning and technological change effects that are hidden in (6) more explicit. To connect these papers to the specification in (6), we need to disentangle the technology/productivity effect from the input effect of abatement. Capturing the former by $T_{P}$ and using a simple iso-elastic specification, we specify the pollution-generating process as:

$$
P=\frac{K^{\eta} E^{1-\eta}}{T_{P}}
$$

where $\eta>1 .^{2}$ In this specification, doubling the rival inputs $E$ and $K$ doubles pollution, but improvements in the technology parameter $T_{P}$ reduce pollution. To capture learning-by-abating, we assume a positive link from abatement to technology:

$$
T_{P}=E^{\gamma}
$$

If $\gamma=1$, (7) and (8) gives $P=(K / E)^{\eta}$ which is consistent with (6) and thus allows for sustainable growth. This justifies the approach in older papers (e.g. Smulders and Gradus, 1996) and newer ones (e.g. Soretz, 2006). 


\subsection{LEARNING-BY-ABATING}

Egli and Steger (2006) open up the black box further and are more explicit about the sources of learning-by-abatement. Their parametric example of the pollution equation can be written as:

$$
\begin{aligned}
& P=\frac{C-C^{\delta} E^{1-\delta} T_{E}}{T_{P}} \\
& T_{E}=E^{\gamma}
\end{aligned}
$$

where $\delta \in(0,1)$. In equation (9), consumption, $C$, rather than (capital) inputs, $K$, is polluting and abatement $E$ has an additive effect rather than a multiplicative effect. The consequence of the latter is that we can distinguish more productive abatement technology (reflected in increases in $T_{E}$ ) from cleaner production technology (reflected in increases in $\left.T_{P}\right) .{ }^{3}$ Equation (10) links abatement technology improvements to levels of abatement and thus captures learning-by-abating. As long as $\gamma>0$, there are increasing returns so that abatement costs fall with the level of abatement. When consumption and abatement grow at a common growth rate, pollution will first rise and then fall. To see this, we rewrite (9)-(10) as:

$$
\begin{aligned}
& P=C\left[1-b C^{\gamma}\right] \\
& b=(E / C)^{\gamma+1-\delta}
\end{aligned}
$$

Now assume $E$ and $C$ grow at the same rate so that $b$ is a constant. Then, for small $C, P$ grows, but for large $C, P$ declines. Andreoni and Levinson (2001) have shown this EKC pattern in a static model with exogenous endowment from which consumption and abatement $(C+E)$ can be financed. Egli and Steger (2006) first demonstrate that when the specification of preferences is appropriately chosen, a corresponding AK-growth model generates a (quasi) balanced growth path along which $E / C$ is indeed constant and $P$ follows the EKC pattern. Second, and more generally, incorporating the specification in (9) in an AK-model, the authors can show how the turning points of the EKC change with technology and preference parameters. Third, they also make explicit the role of (Marshallian) externalities and the implications for corrective taxation. For example, learning could take place on the economywide level so that technology $T_{E}$ is determined by economy-wide abatement and individual small firms can hardly affect $T_{E}$ and take the level of technology as given. 


\subsection{CLEAN TECHNOLOGY ADOPTION}

Cunha-e-Sá and Reis (2006) are even more explicit about the technological progress in abatement. They focus entirely on pollution reduction through changes in technology (increases in $T_{P}$ ) and abstract from instantaneous abatement possibilities (in terms of equation (7), they set $\eta=1$ ). In particular, they assume that in order to have less pollution per unit of capital, a new technology has to be installed. Because of adjustment, technological change is discontinuous: at discrete times the economy adopts a cleaner technology, and at periods at which there is no switch to a new technology, pollution necessarily increases with production. Note that the cleaner technology is applicable nation-wide, so that we may refer to a "general purpose technology" (as in Helpman 1998). Although the authors consider a single adoption only, a series of sequential adoptions could allow for a constant or declining trend in pollution. This would go along with a sequence of investment expenditures, which is similar to the ongoing abatement expenditures in the model with flow-abatement $E$ only.

The paper investigates when economies optimally choose to adopt the cleaner technology and how the change in technology affects growth in the economy. While the usual EKC literature argues that environmental policy reacts to growth in income, the reverse effect is actually also important in a general dynamic equilibrium setting. Indeed, knowing that a cleaner technology that reduces pollution per unit of capital will be available in the future, society values capital more than without adoption, which increases investment and growth. Accordingly, the paper finds that growth of consumption and capital accelerates prior to the adoption date, while these variables grow at a constant rate in the absence of adoption.

\subsection{UNCERTAINTY AND THE VULNERABILITY EFFECT}

In the benchmark model it is attractive to spend on pollution reduction because it boosts utility and productivity, cf. (3)-(4). Soretz (2006) adds a third reason to reduce pollution: reductions in vulnerability to shocks. She assumes expected aggregate production equals $A K$, as in (1), but actual income is subject to exogenous shocks, the effects of which are larger the poorer environmental quality is. In particular, actual output is given by:

$$
Y=K \cdot\left[A+P^{\psi} v d z / d t\right]
$$

where $z$ is the stochastic variable (following a Wiener process) capturing the shocks to aggregate income, and $v$ and $\psi$ are parameters. The bigger $P^{\psi} v$, the bigger the impact of a given shock $d z / d t$. Hence $\psi$ 'measures the effect of pollution on vulnerability to shocks. A risk-averse society spends more on abatement to mitigate the vulnerability effect. This crowds out investment in 
physical capital and tends to reduce growth. However, the risk itself may at the same time increase savings for precautionary motives. Moreover, higher spending on abatement may strengthen the productivity effect (see (3)). Both forces tend to increase the rate of economic growth. The paper sorts out the counteracting effects and formulates implications for optimal environmental taxation.

\section{Spatial Interaction}

So far we have ignored the international and spatial aspects of resource dynamics. Different national economies (or different local communities) have their own specific characteristics, and international (or inter-community) contacts might give rise to convergence or divergence over time of resource use patterns. Geographical specialization in resource use may change resource dynamics directly. Indirectly, resource use is affected by the macroeconomic dynamics stemming from the accumulation of complementary assets and spatial diffusion of new technologies, as well as the social dynamics related to the spatial spillovers of social rules.

\subsection{INTERNATIONAL PRODUCTIVITY CONVERGENCE}

Growth and environmental degradation may be decoupled by substitution of clean for dirty inputs in production. Since such substitution is ruled out in the one-factor AK production function (1), we need to turn to an extended standard multi-input production like the following:

$$
Y=A K^{\alpha} L^{\beta} R^{1-\alpha-\beta}
$$

where $A$ is technology, $K$ capital, $L$ labour, and $R$ a polluting input. With the example of climate change and air pollution in mind, one can interpret the polluting input $(R)$ as energy. Pollution generated is proportional to energy, $P=\pi_{R} R$, where $\pi_{R}$ is the pollution content of energy (e.g. carbon content). The Cobb-Douglas specification in (11) implies a unitary elasticity of substitution, which is restrictive and perhaps unrealistic, but suffices to illustrate some insights that survive with lower substitution possibilities.

The key difference with the AK production function is that in (11) there are diminishing returns to capital and that there is substitution between capital and pollution (polluting inputs). To explore the implications, we derive from (11) the following expressions for average productivity of capital and the amount of pollution per unit of output (which we will label the pollution intensity):

$$
\frac{Y}{K}=A\left(\frac{L}{K}\right)^{\beta}\left(\frac{R}{K}\right)^{1-\alpha-\beta}
$$




$$
\frac{R}{Y}=A^{-1 /(1-\alpha-\beta)}\left(\frac{Y}{L}\right)^{\beta /(1-\alpha-\beta)}\left(\frac{Y}{K}\right)^{\alpha /(1-\alpha-\beta)}
$$

The productivity of capital is no longer a constant $A$, as it was in (1), but declines with capital under the standard neo-classical assumption of diminishing returns to capital (i.e. $0<\alpha, \beta<1$ ). Due to input substitution, capital productivity increases with energy use (and hence with pollution). Furthermore, in (13) capital is no longer polluting, as it was in (7), but is in fact a clean substitute for polluting inputs in production. Finally, we note that technological change (increases in $A$ ) reduces the pollution intensity: it reduces inputs per unit of output and therefore reduces pollution per unit of output.

Crucial in moving to more sustainable growth is the reduction in energy use per unit of output. According to (13), this is possible by relying more on clean inputs, $L$ and $K$, in production. The question is whether and where this is possible. We find an elementary answer if we close the model by the Solowlike assumption of a fixed savings rate. A fixed fraction, say $s$, of output is assumed to be invested in capital so that capital grows at rate $s Y / K$. Hence capital grows quickly when capital productivity $Y / K$ is large. Note from (13) that a large capital productivity $Y / K$ also implies a high pollution intensity. A fast rate of growth of capital implies that capital productivity falls over time, see (12), and that pollution intensity falls, see (13). Hence, we arrive at a convergence result: a high initial pollution intensity implies fast reductions in pollution intensity over time, and vice versa, low pollution intensities imply slow reductions in pollution intensity. Countries with differences in pollution intensity therefore tend to converge in terms of pollution intensity.

An alternative source of convergence in pollution intensities is technology diffusion. There exist enormous international differences in technology (total factor productivity). Poor countries not only have relatively little capital (and hence high capital productivity $Y / K$ and high pollution intensity $R / Y$ ), but also relatively low technology levels $A$, which gives scope for imitation and absorption of foreign technologies, relatively fast growth in $A$ and hence relatively fast reductions in pollution intensities.

Mulder and De Groot (2006) test the convergence hypothesis for pollution intensities within a production function framework, assuming energy is the polluting input. In doing so, they compare their results with convergence in labour productivity. They emphasise the importance of studying dynamics both at the aggregate and sectoral levels, as data aggregation to single country observations may obscure sectoral convergence. They use data from 4 main sectors and 10 sub-sectors in manufacturing of 14 OECD countries in the period 1970-1997. They first observe that cross-country 
variation of energy productivity is much higher than that of labour productivity. In addition, the authors find evidence for conditional convergence of energy and labour productivities in most but not all sectors of the economy. It is important to note that the results for $\beta$-convergence in their paper are conditional on country-specific conditions, so that absolute international productivity differences are predicted to persist in the long run. Notably, in the $\sigma$-convergence analysis energy productivities are found to diverge on a macroeconomic level, so that scale, market and policy effects within countries are confirmed to be essential for the productive use of resources.

\subsection{INTERCOMMUNITY SOCIAL DYNAMICS}

Local communities may not only differ with respect to resource availability and productivity in harvesting, they may also be governed by different social norms concerning cooperation. These norms are subject to their own (social) dynamics. Studying the interaction between resource dynamics and social dynamics is rewarding in at least two respects. First, often policy is faced with a situation characterized by local communities and a spatial distribution of activities. Second, the need for policy is weakened by the capacity of some of these systems to spontaneously generate social norms. Especially in relation to natural resource use, local communities can involve local mechanisms of monitoring and control, which (partially) replace hierarchical public policy. The combination of resource dynamics and spatial structure thus is of relevance to the formulation of optimal resource policies or institutional arrangements.

In the paper of Noailly, Van den Bergh, and Withagen (2006) agents are assumed to harvest a common pool resource. The agents, who are either cooperators, defectors, or enforcers, are located on a circle, observing the actions of their nearest neighbours only. The specific assumption is that agents can enforce common harvesting norms by punishing the defectors not harvesting in a sustainable manner. Thus the set-up allows for a rich structure of local and global interactions in the economy; the latter consist of the impact of aggregate harvesting and the overall stock of the resource on harvesting strategies of individuals. After providing theoretical results and performing extensive numerical analysis, the authors conclude that, unlike in the previous literature, the three strategies can co-exist in a large variety of constellations, while cooperators are very likely to be present at all times. Furthermore the authors emphasise that, when resource dynamics are included, cooperative equilibria become even more likely. 


\section{Conclusions}

We have argued that studies that combine resource dynamics with macroeconomic dynamics and/or social dynamics provide new insights into the issues of sustainability, the turning points of the Environmental Kuznets Curve, technology adoption, protection against environmental disasters, pollution intensity convergence, and local cooperative behaviour in resource extraction. We have shown an underlying and unifying framework of modelling production, pollution and abatement for these topics. We expect future work to deal with a more detailed analysis of different types of technological progress in production and abatement technology, the role of uncertainty and radical technological change, and the micro-economic foundations of semi-reduced-form modelling of abatement. We hope that in the future the links between dynamic theoretical models and econometric time-series or panel analysis will be further strengthened.

\section{Notes}

1. Let $s$ be the savings rate $s=(d K / d t) / Y$, which is by definition constant along a balanced growth path. Then $K$ grows at rate $(d K / d t) / K=s Y / K=s A=s a(P)=s a(P(K / E, C / E, 1))$, which is a constant. Since $A$ is a constant, $Y$ and $K$ grow at the same constant growth rate.

2. The iso-elastic specification has the problem that zero abatement $(E=0)$ implies infinite pollution (Brock/Taylor 2005, page 1805). Therefore, (7) should be interpreted to hold only for a minimum level of abatement. A similar problem arises with the iso-elastic learning function in (8). These undesirable properties can be easily removed by replacing (7) and (8) by $\left(7^{\prime}\right) P=T_{P}^{-1} K \min \left\{1,(E / K)^{-(\eta-1)}\right\}$ and $\left(8^{\prime}\right) T_{P}=\max \left\{T_{0}, E^{\prime \prime}\right\}$, respectively. The threshold in $\left(7^{\prime}\right)$ implies that with zero abatement, pollution is proportional to capital and that a minimum amount of abatement is required before abatement starts to be effective. The threshold in $\left(8^{\prime}\right)$ implies that learning starts only for large enough abatement levels. As long as $\gamma=1$ and $T_{0}<K<E$, we still find $P=(K / E)^{\eta}$.

3. Alternative labels are pollution-augmenting and abatement-augmenting technological change. The distinction is impossible to make in the Cobb-Douglas specification of (7), exactly like labour-augmenting and capital-augmenting technological change are equivalent in Cobb-Douglas production functions.

\section{References}

Aghion, P. and P. Howitt (1998), Endogenous Growth Theory, Cambridge, MA: MIT Press. Andreoni, J. and A. Levinson (2001), 'The simple analytics of the Environmental Kuznets Curve', Journal of Public Economics 80(2), 269-286. AH 1998.

Bradford, D. F., R. A. Fender, S. H. Shore and M. Wagner (2005), 'The Environmental Kuznets Curve: Exploring a Fresh Specification', Contributions to Economic Analysis \& Policy: Vol. 4: No. 1, Article 5 http://www.bepress.com/bejeap/contributions/vol4/iss1/art5. 
Brock, W. A. and M. Scott Taylor (2004), 'The Green Solow Model', NBER Working Paper No. 10557.

Brock, W. A. and M. Scott Taylor (2005), 'Economic Growth and the Environment: A review of theory and empirics', in: P. Aghion, S. N. Durlauf, eds., Handbook of Economic Growth, Volume 1B. Elsevier.

Cunha-e-Sá, M. A. and A. B. Reis, (2006), 'Optimal Timing of Adoption of a Green Technology', Environmental and Resource Economics DOI 10.1007/s10640-006-9045-8.

Egli, H. and T. M. Steger (2006), 'A Dynamic Model of the Environmental Kuznets Curve: Turning Point and Public Policy', Environmental and Resource Economics DOI 10.1007/ s10640-006-9044-9.

Helpman, E. (1998), General Purpose Technologies and Economic Growth, Cambridge, MA: MIT Press.

Mulder, P. and H. L. F. de Groot (2006), 'Sectoral Energy- and Labour-Productivity Convergence', Environmental and Resource Economics DOI 10.1007/s10640-006-9042-y.

Noailly, J., J. C. J. M. van den Bergh and C. A. A. M. Withagen (2006), 'Spatial Evolution of Social Norms in a Common-pool Resource Game', Environmental and Resource Economics DOI 10.1007/s10640-006-9046-7.

Romer, P. (1986), 'Increasing returns and long run growth', Journal of Political Economy 94, 1002-1037.

Smulders, S. and R. Gradus (1996), 'Pollution abatement and long-term growth', European Journal of Political Economy 12, 505-532.

Soretz, S. (2006), 'Efficient Dynamic Pollution Taxation in an Uncertain Environment', Environmental and Resource Economics DOI 10.1007/s10640-006-9041-z.

Stokey, N. (1998), 'Are there limits to growth', International Economic Review 39(1), 1-31. 